\section{Beefing about the risks posed by the French BSE epidemic}

Sir - In my capacity as chairman of the UK Food Standards Agency, I read Christl Donnelly's paper (Nature 408, 787-788; 2000) while it was being prepared for publication, and would like to comment on issues of food safety and policy raised by Donnelly's conclusions. Although the study of the French BSE epidemic is made in the context of the situation in the United Kingdom, there are some points that may have broader implications for the European situation as a whole.

Following the 4 December meeting of the Agriculture Council, the European Commission has announced a series of new measures which will have a significant impact in reducing risk in the future. These include a complete ban on the use of mammalian meat and bone-meal for all livestock, the exclusion of all bovine intestine from the food chain and the introduction of an over-30-month (OTM) rule for all member states. Cattle over 30 months will only be allowed into the food chain if they have been tested for BSE and found negative.

This year, the United Kingdom has had ten times as many cases of BSE as France, and yet, according to Donnelly, the current risk of eating an animal close to developing clinical BSE is substantially higher in France than in Britain (52 such animals going into the food chain in France versus 1.2 in the United Kingdom). The explanation for this is that Britain, uniquely, has not allowed any animals over the age of 30 months to go into the food chain, and virtually no animals are close to clinical BSE by this age. The studies of tissue infectivity carried out so far show that most infectivity occurs in animals within the last 12 months before clinical symptoms appear. Almost all infectivity in these animals is removed in the "specified risk material" that is excluded from the food chain.

Donnelly's conclusions depend on three key assumptions: (1) that the age distribution for the onset of clinical BSE in France, reflecting a combination of the incubation period and the age at infection, is the same as in the United Kingdom; (2) that French and UK cattle populations have similar survivorship curves; (3) that $100 \%$ of clinical cases were reported in France in 2000, with under-reporting in earlier years, as was the case in the UK. The assumption of complete reporting this year may prove to be optimistic, in which case, risk from French beef will increase roughly in proportion to the degree of under-reporting this year (in other words,
$50 \%$ reporting would double the risk).

Because of the uncertainties about these three assumptions, especially the third, it is better to think of the relative risks as being an order of magnitude higher in France, rather than to focus on precise numbers. It is also important to keep the risks in perspective. Under Donnelly's assumptions, the risk of consumer exposure to animals close to clinical infection in the food chain in France today is similar to the risk in Britain, say, three or four years ago. The United Kingdom's risk is going down as the epidemic declines.

For consumers of French beef in other European Union countries, the risks will be the same as for French beef in France. However, in order to look at the risks to British consumers from eating imported French beef, one must make an assumption about how effective enforcement of the OTM rule is for imports.

If the OTM rule is fully enforced, Donnelly estimates that the risk from French beef imported to Britain is essentially zero (no cattle within twelve months of developing clinical BSE). If the rule is not fully enforced, the risk scales in proportion to the frequency of breach. Given informal indications to the Food Standards Agency from local authorities that the rule is generally followed in Britain, Donnelly's example of $75 \%$ enforcement seems reasonable, and yields a relative risk from French imports of the same order of magnitude as the estimate for Britain's domestic beef.

Donnelly's study (accepting its assumptions) indicates that there is no risk case for a ban on beef imports from France to the United Kingdom - even though this would be a populist move in Britain, given that the French banned UK beef in spite of their own higher risk. It also highlights the importance of effective enforcement of the OTM rule for protecting consumers in Britain, and shows why the European Commission's new plan for an OTM-like rule (the exemption being tested animals) throughout Europe is a key step forward.

Although Donnelly focuses on French carcass meat, comparable if not greater risks to UK consumers could arise from the import of meat products (such as pâtés and salamis) which usually contain beef, as it is difficult to ascertain the age and provenance of any cattle-derived contents.

The precautionary principle, unfortunately, has come to mean all things to all lobbyists. But in the European Commission's view it should start from the available evidence, acknowledging uncertainties; it should be consistent; it should be proportionate to the risk; and it should require frequent reassessment of the risks in the light of new evidence. Against this background, the UK Food Standards Agency will continue to update its assessment of risk and consequent need for action. However, the European Commission's decision to introduce the new EU-wide measures (including an OTM-like ban) will, when implemented on 1 January 2001, enhance protection against BSE risks for consumers in all member states. John Krebs Chairman, Food Standards Agency, PO Box 30080, London SE1 6YA, UK

\section{Acid test finally wiped out vitalism, and yet ...}

Sir-Sunetra Gupta in her Millennium Essay "A victim of truth" (Nature 407, 677; 2000) astutely points out the dilemma in which the Swedish chemist Jons Berzelius found himself when his student Friedrich Wöhler declared in 1828 that he could make urea, a typical product of living organisms, from inorganic sources.

Gupta describes Berzelius's antagonism to the atheistic materialism that abandonment of vitalism would bring.

There was, however, another factor. An important reason that vitalism did not immediately disappear after Wöhler's discovery is given in J. R. Partington's textbook A History of Chemistry (Macmillan, London, 1961).

Wöhler synthesized urea from ammonium cyanate. The cyanate was obtained from cyanide, which in those days was made from ferrocyanide which in turn was extracted from the wastes from tanning factories. Thus, to an adherent of vitalism, the urea had not been derived from purely inorganic sources but had a vital component.

The death-knell of vitalism in chemistry was sounded in 1845 when Hermann Kolbe showed that acetic acid, a common end product in living organisms, could be "composed by synthesis from its elements". This was the first use of the word 'synthesis' in a memoir on organic chemistry. Sidney Toby

Department of Chemistry, Rutgers, the State University, Piscataway, New Jersey 08854, USA

\section{we need a metaphor to explain life's mystery}

Sir - Sunetra Gupta, in her poetic and accurate Millennium Essay on vitalism, concludes that "we remain inclined to believe that the analysis of life does not 
detract from its ultimate mystery". Vitalism as biological metaphor survived for so long, she says, because it provided a basis for retaining our primary experience of life as a mystery at the same time that we decompose the mystery through scientific analysis.

Holding these two ideas together may be seen as a form of cognitive dissonance, a state of mind producing considerable discomfort and mental disorder. Allegiance to our current metaphor - 'life is a machine' - has led to much progress in medicine and agriculture, for example, but also caused great harm to human beings and the worldwide environment.

Many formal mathematical and other scientific arguments deny the machine model in biology, and it might be a good start to reveal these arguments to our students more than we do now.

We could start, perhaps, with Niels Bohr's worry that "the minimum freedom we must allow the organism will be just large enough to permit it, so to say, to hide its secrets from us"1, and end with Diethard Tautz's treatment of a biological equation equivalent to Heisenberg's uncertainty relationship in physics suggesting that attempts to predict biological function from genetic information may require "experiment on an evolutionary scale".

Our inclination to believe in life's ultimate mystery appears to have a declining vitalistic (or any other) force in the machine world of everyday life. Gupta does a real service in reminding us how important metaphor is in science. Just perhaps, we could find something closer to our primary experience of life than our current machine metaphor as we approach the analysis of living things.

A little bit of scientific philosophy and physical theory like this might, if not vitalize, then at least brighten up those deterministic lectures in Molecular Biology 101.

\section{Richard Strohman}

Department of Molecular and Cell Biology, University of California at Berkeley, 229 Stanley Hall, Berkeley, California 94720-3206, USA

1. Bohr, N. Nature 131, 458 (1933).

2. Tautz, D. Trends Genet. 16, 475-477 (2000).

\section{Ecology needs theory as well as practice}

Sir - In his Millennium Essay (Nature 408, 293; 2000), Jim Smith proposes that ecological theory is generally untestable, and therefore that ecology should concentrate less on theoretical explanation and more on finding applied solutions to humankind's environmental problems.
Although his concern for solving environmental problems is widely shared by theoretical and empirical ecologists alike, Smith's call for use of Robert Peters's 'predictive ecology' in place of a more conceptually grounded approach runs the risk of leading ecology into a dead end of blind empiricism.

Smith overstates Karl Popper's influence over the philosophy of science. Science is a much broader and less formally rigorous enterprise than Popper envisioned. In The Structure of Scientific Revolutions (University of Chicago Press, Chicago, 1970) Thomas Kuhn, for example, argued that a large component of cultural subjectivity determines the outcome of the scientific enterprise. His concept of paradigm shifts implicitly assumes that political interactions among scientists are at least as important as empirical verification of hypotheses in deciding the outcome of scientific progress. Science can still uncover much about the natural world, even if it is such a culturally dominated social system. Neither Popper's views nor a less restrictive philosophy of science justifies the abandonment of conceptual work in ecology.

Progress in ecology has been hampered in the past by assuming that complex ecological systems can be adequately described by relatively simple linearized models, but even those who originated this approach realized its limited usefulness. Significant advances in science are not based solely on the success of a model in predicting some unknown phenomenon.

Smith's example of relativity is a case in point. The real significance of relativity to physics was not its ability to predict the bending of light by large, massive celestial bodies. Rather, relativity revolutionized physics by revealing an underlying conceptual unity to disparate phenomena. Relativity did not supplant classical physics, it simply limited the spatial and temporal scales to which the rich theoretical framework of classical physics could be applied with acceptable precision.

Ecology will make real scientific progress only by developing a rigorous conceptual framework that can be tested with appropriately sophisticated statistical methodology. Ecological systems are indeed complex. Simplistic semi-empirical relationships based on vague, poorly parameterized, linear statistical models of single systems provide only approximate or temporary solutions to environmental problems. They do not determine which problems are of greatest importance or how limited resources might be optimally allocated.

Only a larger, more comprehensive conceptual framework can provide such guidance. Explorations of ecological theory are nice work and are essential to the progress of ecology as science.

\section{Brian A. Maurer}

Department of Fisheries \& Wildlife and

Department of Geography, Michigan State

University, East Lansing, Michigan 48824, USA

\section{Pressure to meet current needs hinders science}

Sir-Your report (Nature 407, 276; 2000) about the World Bank giving higher priority to science was a welcome reminder that, unfortunately, national and international 'development' organizations have given short shrift to the scientific and technological base that is essential to enable countries to prosper.

In December 1992, former US president Jimmy Carter and I, with a distinguished task force from the Carnegie Commission on Science, Technology and Government, released a report entitled "Partnerships for Global Development: The Clearing Horizon". We underscored the critical importance of science and technology in economic development along with the imperative for global cooperation.

During the 1990s, however, major donors yielded to pressure to use almost all aid resources for distributing food and medicine today instead of improving agricultural productivity and vaccines for tomorrow. Further, developed countries suffered 'aid fatigue' because foreign assistance seemed to be a perpetual handout rather than a catalyst for economic independence. Investment in science and education was also marginalized by grave difficulties in creating financial stability with honest, democratic governance under the rule of law.

US secretary of state Madeleine Albright, seeing a growing need for science and perhaps sensing the new rustlings at the bank, recently named a science adviser: Norman Neureiter, a chemist with an extraordinarily sophisticated understanding of how universities and the private sector interact with the public sector to spark economic growth. This long-needed graft of science onto US diplomacy will demand intensive care for many months.

Along similar lines, don't expect a quick turnaround from the World Bank's higher priority on science. The bank will have to rethink its mission and operations to decide how global technological change meshes with its economic strategy.

Rodney W. Nichols

New York Academy of Sciences, 2 East 63rd Street, New York, New York 10021, USA 